\title{
DIRECIONAMENTOS DA TECNOLOGIA INDUSTRIAL DE CÉLULAS A COMBUSTÍVEL DE ÓXIDOS SÓLIDOS
}

Daniel Z. de Florio*\# e José A. Varela

Instituto de Química, Universidade Estadual Paulista, CP 355, 14801-970 Araraquara - SP, Brasil

Fabio C. Fonseca, Eliana N. S. Muccillo e Reginaldo Muccillo

Instituto de Pesquisas Energéticas e Nucleares, Travessa R 400, 05508-000 São Paulo - SP, Brasil

Recebido em 4/4/06; aceito em 16/3/07; publicado na web em 17/7/07

\begin{abstract}
DIRECTIONS OF THE INDUSTRIAL DEVELOPMENT OF THE SOLID OXIDE FUEL CELLS TECHNOLOGY. This manuscript shows an overview of the solid oxide fuel cell (SOFC) technology based on industrial developments. The information presented has been collected mostly at conferences that the authors attended. It is observed that several companies have been pursuing the development of the SOFC technology. Significant advances in stability and power density have raised the economic interest in this technology recently. It is revealed that the SOFC materials are essentially the same ones that have been used in the past decades, and that the two most important designs of pre-commercial SOFC prototypes are the tubular and planar ones.
\end{abstract}

Keywords: solid oxide fuel cell; industrial development; energy production.

\section{INTRODUÇÃO}

As células a combustível de óxidos sólidos (CCOS, SOFC "Solid Oxide Fuel Cell") são os dispositivos conhecidos mais eficientes para a conversão eletroquímica de um combustível em energia elétrica ${ }^{1}$. O funcionamento destes dispositivos baseia-se nos princípios eletroquímicos das células a combustível, onde a energia química de um combustível é convertida diretamente em energia elétrica, sem os limites impostos pelo ciclo de Carnot às máquinas térmicas ${ }^{2}$. Nas CCOS as reações eletroquímicas de oxidação do combustível e de redução do oxidante ocorrem na interface gás (combustível ou oxidante) condutor eletrônico/condutor iônico, chamada de contorno de fase tripla ou tripla fase reacional. Uma célula unitária de óxidos sólidos consiste, essencialmente, de dois eletrodos porosos (catodo e anodo) separados por um eletrólito sólido denso. No anodo o combustível é oxidado, reagindo com os íons oxigênio provenientes do eletrólito, liberando elétrons e formando água. Os elétrons produzidos no anodo são transportados pelo circuito externo até o catodo onde o oxigênio é reduzido e os íons formados atravessam o eletrólito em direção ao anodo, completando a reação. $\mathrm{O}$ trabalho elétrico é realizado pelos elétrons do circuito externo. Na Figura 1 são apresentados o esquema de funcionamento e a reação global de uma CCOS.

Considerando-se a geração de energia distribuída, a CCOS apresenta diversas vantagens em relação a outras tecnologias concorrentes, como motores a diesel e microturbinas a gás, ou mesmo outros tipos de células a combustível. Na Figura 2 é mostrado um diagrama comparativo de algumas propriedades de sistemas de geração (estacionária) de energia elétrica. Pode-se observar que as CCOS são os dispositivos que apresentam maiores eficiências e menores emissões de poluentes comparativamente às outras tecnologias. Entretanto, o principal fator que inibe a comercialização destes dispositivos ainda é o elevado custo da tecnologia.

Entre as diferentes tecnologias de células a combustível, a CCOS destaca-se por ser o único dispositivo inteiramente no estado sólido. Outra importante característica que diferencia as CCOS das

*e-mail: dzflorio@ipen.br

\#Endereço atual: Universidade Federal do ABC

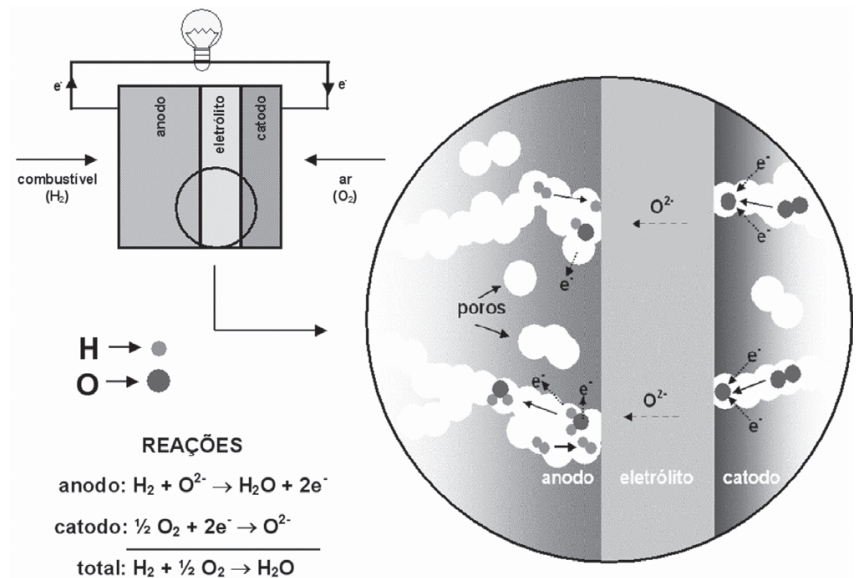

Figura 1. Diagrama esquemático do funcionamento e das reações em células a combustível de óxidos sólidos, utilizando eletrólitos condutores de íons oxigênio

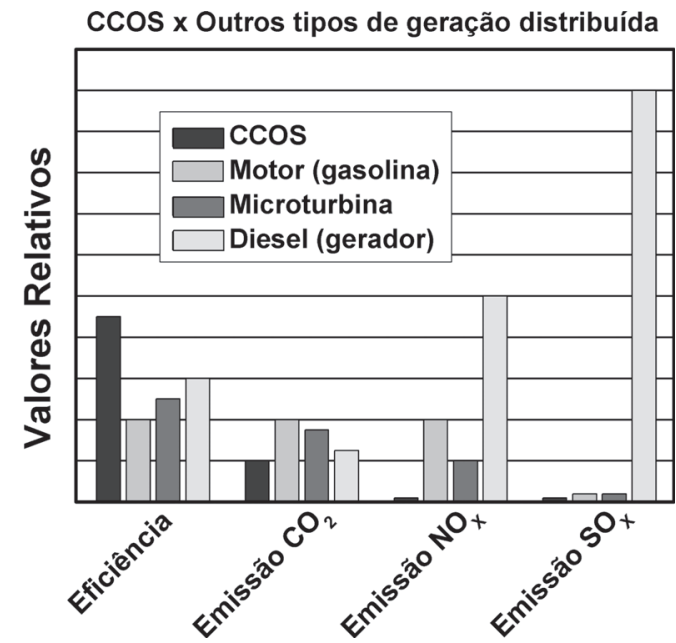

Figura 2. Diagrama comparativo de algumas propriedades de sistemas de geração de energia elétrica 
demais células a combustível é a sua temperatura de operação. As temperaturas relativamente elevadas de operação (entre 500 e 1000 ${ }^{\circ} \mathrm{C}$ ) conferem a estas células importantes propriedades, como alta eficiência e flexibilidade de combustível. Por outro lado, os maiores desafios tecnológicos a serem superados para a viabilização comercial destes dispositivos também estão relacionados com estas altas temperaturas. Problemas relativos à degradação em longos períodos de operação refletem os diversos fenômenos induzidos termicamente em seus materiais componentes. Nas CCOS, devido às altas temperaturas de operação e fabricação dos materiais componentes, degradações associadas com, por exemplo, envelhecimento térmico, incompatibilidade de coeficientes de expansão térmica e sinterização, são apontadas como críticas para o desenvolvimento desta tecnologia.

Neste sentido, podem ser destacadas algumas importantes linhas de desenvolvimento nas pesquisas referentes à CCOS: novos processos e materiais; durabilidade/confiabilidade e combustíveis hidrocarbonetos. Estas linhas de pesquisa são muitas vezes relacionadas entre si e pautadas quanto à redução de custos, o que, em alguns casos, acaba por resultar no objetivo de redução da temperatura de operação (entre 500 e $800{ }^{\circ} \mathrm{C}$ ). Os resultados dessas pesquisas são geralmente apresentados nos meios de divulgação científica (periódicos e conferências). Por outro lado, a maior parte do desenvolvimento tecnológico realizado por empresas que visam a comercialização destas células tem divulgação, evidentemente, mais restrita por motivos de preservação da propriedade intelectual. Entretanto, estas empresas têm apresentado alguns de seus resultados em conferências especializadas da área. Embora as informações sejam relativamente limitadas, é possível estabelecer a partir delas um panorama das tendências tecnológicas seguidas pelas empresas envolvidas neste desenvolvimento.

$\mathrm{O}$ interesse comercial neste dispositivo é determinado pelas propriedades diferenciadas destas células a combustível. Um importante aspecto motivador do desenvolvimento comercial da CCOS é a possibilidade de uso de diferentes combustíveis. As CCOS podem operar usando hidrogênio obtido a partir da reforma de um combustível primário, sem a necessidade de purificação nos mesmos níveis exigidos para as células a combustível poliméricas, nas quais 10 ppm de CO são suficientes para degradar o seu desempenho. Na CCOS, as altas temperaturas de operação favorecem os processos eletroquímicos e diminuem a sensibilidade aos contaminantes (exceção feita ao enxofre). Portanto, a CCOS pode operar diretamente com diversos combustíveis (metano, metanol e etanol, por exemplo), que podem ser processados no corpo da célula por reforma interna ou oxidação $\operatorname{direta}^{1-3}$. Neste contexto, a pesquisa de CCOS visando o uso de etanol pode ser considerada como um importante nicho tecnológico que pode ser desenvolvido no Brasil. Na Figura 3 é apresentada uma representação esquemática da complexidade do combustível em função da temperatura de operação para alguns tipos de células a combustível; pode-se notar que para as células de baixa temperatura de operação existe a necessidade de reformadores externos.

Aliado à flexibilidade de combustível, outro aspecto importante para a comercialização das CCOS é que estas podem ser projetadas para diferentes aplicações em uma ampla faixa de potência (de W a MW). Na faixa de altas potências são previstas CCOS da ordem de MW, possivelmente operando em conjunto com turbinas a gás, resultando em altas eficiências de geração $(\sim 80 \%)$. As aplicações estacionárias também têm sido desenvolvidas na escala de 10 $\mathrm{kW}$ para, por exemplo, o fornecimento de energia elétrica para residências. Mais recentemente, uma possível aplicação de CCOS de baixas potências $(\leq 1 \mathrm{~kW})$, como unidades auxiliares de potência para aplicações em veículos de transporte, também tem sido considerada. Entretanto, os protótipos desta tecnologia mais desenvolvidos e testados por longos períodos (> 1000 h) têm potência de 1-3 kW. Nestes sistemas já são alcançados níveis de eficiência $(>35 \%)$, de degradação $(<4 \% / 1000$ h) e custo projetado $(<$ $800 \mathrm{US} \$ / \mathrm{kW}$ ). Estes são os valores estabelecidos para a fase atual do projeto do DOE. As metas definidas pelo DOE para as empresas participantes de seus programas de desenvolvimento de CCOS prevêm para o ano 2010 que a eficiência deve atingir valores superiores a $50 \%$ e a degradação e o custo devem atingir valores equivalentes a cerca de metade dos atuais.

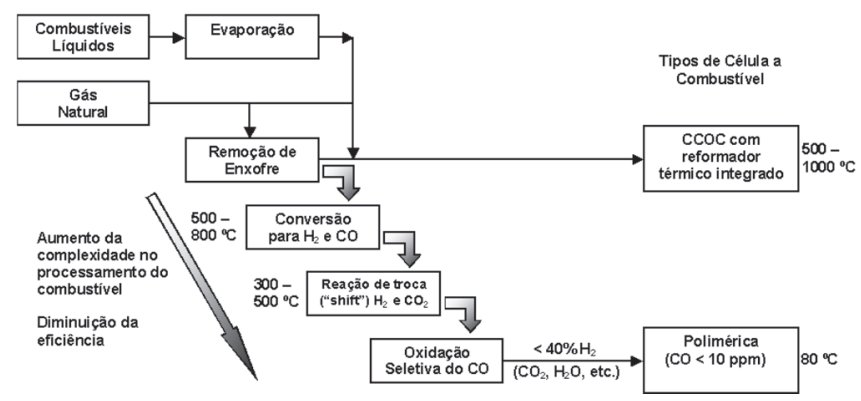

Figura 3. Diagrama evidenciando a complexidade do combustível em relação à temperatura de operação de alguns tipos de células a combustível

O conjunto de propriedades da CCOS tem atraído o interesse comercial nestes dispositivos de geração de energia elétrica. Uma estimativa deste interesse pode ser feita através dos números envolvidos nos investimentos para o desenvolvimento desta tecnologia e pelo número e porte de companhias engajadas no desenvolvimento da CCOS. Acredita-se que cerca de 100 milhões de dólares/ ano têm sido investidos mundialmente na pesquisa dessas células a combustível. Existem cerca de 30 companhias, distribuídas pela Ásia, Oceania, Europa e América do Norte, que estão envolvidas diretamente com o desenvolvimento de CCOS. Estima-se que estas empresas empreguem cerca de 1400 funcionários no desenvolvimento da $\mathrm{CCOS}^{4}$. Entre estas empresas, cerca de 6 são companhias unicamente de CCOS, ou seja, têm a CCOS como seu negócio principal. Também deve ser destacado o interesse de empresas de grande porte nas CCOS, como General Electric, Siemens e Mitsubishi. Ainda não existem CCOS comerciais e, atualmente, a maior parte das companhias com um alto grau de desenvolvimento nesta área encontra-se na fase de desenvolvimento e iniciação de fabricação e testes de protótipos.

Ao contrário dos artigos de revisão sobre células a combustível de óxidos sólidos, que se concentram geralmente em resultados de pesquisa essencialmente acadêmica, no presente trabalho é apresentado um panorama desta tecnologia a partir de dados referentes aos desenvolvimentos tecnológicos que visam a comercialização destas células a combustível. Este enfoque permite uma avaliação dos principais aspectos tecnológicos destas células a combustível quando colocadas à prova nas condições mais próximas do uso prático, como por exemplo, nas situações de testes de campo por longos períodos de tempo, e visando sua competitividade comercial.

\section{MATERIAIS}

Os materiais empregados nas CCOS podem ser classificados em termos dos componentes da célula unitária, formada pelo anodo, eletrólito e catodo, e o interconector. Cada um destes materiais tem propriedades específicas e deve atender a requisitos bastante rigorosos para a fabricação e operação das CCOS. De maneira ge- 
ral, componentes com propriedades otimizadas são fundamentais para o bom desempenho destes dispositivos. Vários trabalhos apresentam em detalhes os materiais, suas propriedades e os rigorosos requisitos aos quais devem atender para sua aplicação em $\operatorname{CCOS}^{5}$.

Os materiais mais utilizados nessas células estão estabelecidos há cerca de 30 anos. São eles: os eletrólitos sólidos à base de zircônia (óxido de zircônio) estabilizada com ítria (ZEI); os anodos compósitos cerâmica-metal, formado pela ZEI com adição de níquel (ZEI/Ni); os catodos à base de manganitas de lantânio dopadas, como o $\mathrm{La}_{0,7} \mathrm{Sr}_{0,3} \mathrm{MnO}_{3}$ (LSM) e os interconectores à base de cromitas de lantânio $\left(\mathrm{LaCrO}_{3}\right)$.

Um grande esforço da pesquisa científica sobre a CCOS envolve a otimização dos materiais componentes mais usados e também o desenvolvimento de materiais alternativos. Entre estas pesquisas podem ser destacadas a busca por novos eletrólitos cerâmicos, com alta condutividade iônica e estabilidade térmica, e as tentativas de substituição dos interconectores cerâmicos por ligas metálicas. Do ponto de vista tecnológico, todas as empresas têm utilizado nas células unitárias os compostos já tradicionalmente estabelecidos para a construção dos dispositivos. Um dos principais fatores que restringem o uso de materiais alternativos é a falta de estabilidade em longos períodos de operação da célula. Isto evidencia que os materiais alternativos pesquisados em escala laboratorial ainda não atingiram o grau de desenvolvimento necessário para sua aplicação ou que os custos envolvidos no emprego destes materiais não são justificados em termos de ganho de desempenho do dispositivo. Os custos associados aos materiais constituem a maior porcentagem do custo total de uma CCOS $(\sim$ $50 \%$ ). Portanto, todo desenvolvimento nesta área deve atender ao princípio de minimização de $\operatorname{custos}^{6}$.
De maneira geral, detalhes sobre a composição exata dos materiais usados, como as dopagens das manganitas e do eletrólito ou a fração volumétrica de Ni nos anodos, são geralmente omitidos. Entretanto, apenas duas companhias optam por condutores iônicos diferentes da ZEI: a Ceres Power (Inglaterra), que desenvolve CCOS de baixas temperaturas de operação $\left(\sim 500{ }^{\circ} \mathrm{C}\right)$ usando eletrólitos à base de céria (óxido de cério) ${ }^{7}$, e a Mitsubishi Materials (Japão) que usa eletrólitos a base de galato de lantânio (óxido de gálio e lantânio) para operação a $800{ }^{\circ} \mathrm{C}^{8}$. Nos catodos das CCOS observa-se que o uso do LSM é o mais difundido; por outro lado, diversas empresas têm optado pelos compostos da família $\mathrm{La}_{1-\mathrm{x}} \mathrm{Sr}_{\mathrm{x}} \mathrm{Co}_{1-\mathrm{y}} \mathrm{Fe}_{\mathrm{y}} \mathrm{O}_{3-\delta}$ (LSCF) ${ }^{9}$ para operação em temperaturas intermediárias $\left(<800{ }^{\circ} \mathrm{C}\right)$. Uma parte considerável das células desenvolvidas comercialmente emprega ligas metálicas como interconectores alternativos ao $\mathrm{LaCrO}_{3}$, as quais em alguns casos ainda têm a função de suporte da célula unitária na configuração planar. Os desenvolvimentos do anodo são estimulados pela utilização de combustíveis hidrocarbonetos. Entretanto, ainda não foi estabelecido um anodo resistente a ciclos de oxidação e inerte à formação de depósitos de carbono com desempenho superior aos compósitos a base de níquel. Outro material componente, empregado em algumas configurações de CCOS, é o selante usado para separar os compartimentos do combustível e do oxidante. Eles são, usualmente, materiais vítreos, mas sua composição consiste em um dos detalhes mais omitidos pelos empreendedores comerciais de CCOS. As exigências para este material são muito restritivas e pesquisas intensas são dedicadas ao desenvolvimento deste componente.

A Tabela 1 mostra uma seleção das principais companhias envolvidas no desenvolvimento de CCOS, os materiais empregados em suas células e a configuração utilizada ${ }^{4,10}$.

Tabela 1. Seleção das principais companhias envolvidas no desenvolvimento de células a combustível de óxidos sólidos, configuração (design) utilizada, materiais empregados, enfoques de desenvolvimento e particularidade de cada sistema/empresa

\begin{tabular}{|c|c|c|c|c|}
\hline Companhia (País) & Configuração & Materiais & $\begin{array}{c}\text { Enfoque de } \\
\text { desenvolvimento }\end{array}$ & Particularidade \\
\hline General Electric (EUA) & Planar & $\begin{array}{l}\text { IC* metálico, } \\
\text { suportada no anodo }\end{array}$ & $\begin{array}{l}\text { Materiais, célula, } \\
\text { Emp**, sistema, } \\
\text { reforma }\end{array}$ & $\begin{array}{c}\text { Camada anodo/eletrólito } \\
\text { preparada por tape } \\
\text { calendering }\end{array}$ \\
\hline $\begin{array}{l}\text { Delphi / Pacific Northwest } \\
\text { Nat. Lab. (EUA) }\end{array}$ & Planar & $\begin{array}{l}\text { IC metálico, suportada } \\
\text { no anodo }\end{array}$ & Célula, Emp & $\begin{array}{l}\text { Sistemas auxiliares } \\
\text { de potência }\end{array}$ \\
\hline Acumentrics (EUA) & Tubular & Suportada no anodo & $\begin{array}{c}\text { Célula, Emp, } \\
\text { sistema, materiais }\end{array}$ & Modelamento \\
\hline ZTek (EUA) & Planar & IC metálico & Célula, Emp, sistema & \\
\hline $\begin{array}{l}\text { Global Thermoelectric/ } \\
\text { Versa Power (Canadá) }\end{array}$ & Planar & $\begin{array}{l}\text { IC metálico, } \\
\text { suportada no anodo }\end{array}$ & $\begin{array}{l}\text { Materiais, célula, } \\
\text { Emp, sistema }\end{array}$ & $\begin{array}{l}\text { Testes bem sucedidos de } \\
50 \text { ciclos térmicos } \\
\text { entre a temperatura de } \\
\text { operação e ambiente }\end{array}$ \\
\hline $\begin{array}{l}\text { Siemens-Westinghouse } \\
\text { (Alemanha) }\end{array}$ & $\begin{array}{l}\text { Tubular, } \\
\text { tubo achatado }\end{array}$ & Suportado no catodo & $\begin{array}{l}\text { Materiais, fabricação, } \\
\text { Emp, sistema }\end{array}$ & $\begin{array}{l}\text { Protótipo funcionando } \\
\text { por mais de } 40.000 \mathrm{~h}\end{array}$ \\
\hline Ceres Power (Inglaterra) & Planar & IC e substrato metálicos & $\begin{array}{l}\text { Materiais, célula, } \\
\text { Emp, sistema }\end{array}$ & $\begin{array}{l}\text { Eletrólito de céria- } \\
\text { gadolínea, temperatura } \\
\text { de operação } 550{ }^{\circ} \mathrm{C}\end{array}$ \\
\hline Sulzer Hexis (Suíça) & Planar circular & $\begin{array}{l}\text { IC metálico, suportada } \\
\text { no eletrólito }\end{array}$ & $\begin{array}{l}\text { Materiais, célula, } \\
\text { Emp, sistema }\end{array}$ & $\begin{array}{l}\text { Possui } 100 \text { protótipos de } \\
1 \mathrm{~kW} \text { em testes de campo }\end{array}$ \\
\hline Topsoe/Risoe (Dinamarca) & Planar & $\begin{array}{l}\text { Desde } 2000 \text { IC metálico, } \\
\text { suportada no anodo }\end{array}$ & $\begin{array}{l}\text { Sistema, materiais, } \\
\text { reforma, célula, Emp }\end{array}$ & $\begin{array}{l}\text { Até } 1999 \text { IC cerâmico, } \\
\text { suportada no eletrólito }\end{array}$ \\
\hline Rolls Royce (Inglaterra) & Planar & $\begin{array}{l}\text { Suportada em substrato } \\
\text { cerâmico poroso }\end{array}$ & $\begin{array}{l}\text { Materiais, célula, } \\
\text { Emp, sistema }\end{array}$ & \\
\hline BMW (Alemanha) & Planar & $\begin{array}{l}\text { IC metálico, } \\
\text { substrato metálico }\end{array}$ & Sistema, Emp & $\begin{array}{l}\text { Sistemas auxiliares de } \\
\text { potência para veículos }\end{array}$ \\
\hline $\begin{array}{l}\text { Forschungszentrum-Jülich } \\
\text { (Alemanha) }\end{array}$ & Planar & $\begin{array}{l}\text { IC metálico, } \\
\text { suportada no anodo }\end{array}$ & $\begin{array}{l}\text { Materiais, célula, } \\
\text { Emp, sistema }\end{array}$ & Modelamento \\
\hline
\end{tabular}


Tabela 1. continuação

\begin{tabular}{|c|c|c|c|c|}
\hline Companhia (País) & Configuração & Materiais & $\begin{array}{c}\text { Enfoque de } \\
\text { desenvolvimento }\end{array}$ & Particularidade \\
\hline Pirelli (Itália) & Planar & $\begin{array}{l}\text { anodo de } \mathrm{Ni}, \mathrm{Cu} \text { e céria } \\
\text { dopada com gadolínea }\end{array}$ & $\begin{array}{l}\text { Materiais, } \\
\text { Combustíveis }\end{array}$ & $\begin{array}{l}\text { Utilização de etanos, } \\
\text { metanol etc. }\end{array}$ \\
\hline Kyocera (Japão) & $\begin{array}{l}\text { Planar, circular } \\
\text { Tubular, tubo } \\
\text { achatado }\end{array}$ & Suportada no anodo & $\begin{array}{l}\text { Materiais, célula, } \\
\text { Emp, sistema }\end{array}$ & \\
\hline $\begin{array}{l}\text { Mitsubishi Materials } \\
\text { (Japão) }\end{array}$ & Planar & $\begin{array}{c}\text { Eletrólito de galato } \\
\text { de lantânio }\end{array}$ & $\begin{array}{l}\text { Materiais, célula, } \\
\text { Emp, sistema }\end{array}$ & $\begin{array}{c}\text { Temperatura de } \\
\text { operação } 800{ }^{\circ} \mathrm{C}\end{array}$ \\
\hline $\begin{array}{l}\text { Mitsubishi Heavy } \\
\text { Industries (Japão) }\end{array}$ & $\begin{array}{c}\text { Planar monobloco, } \\
\text { Tubular }\end{array}$ & $\begin{array}{c}\text { IC cerâmico, suportada } \\
\text { no eletrólito (Planar) }\end{array}$ & $\begin{array}{l}\text { Materiais, célula, } \\
\text { Emp, sistema }\end{array}$ & $\begin{array}{l}\text { Suportada em tubo } \\
\text { poroso, conexão em } \\
\text { série (Tubular) }\end{array}$ \\
\hline $\begin{array}{l}\text { Nihon Gaishi } \\
\text { (NGK) (Japão) }\end{array}$ & Planar & Suportada no anodo & Materiais, célula & \\
\hline Toto (Japão) & Tubular & Suportada no catodo & $\begin{array}{l}\text { Materiais, célula, } \\
\text { Emp, sistema }\end{array}$ & $\begin{array}{l}\text { Em } 2004 \text { iniciou projeto } \\
\text { em colaboração com a } \\
\text { Hitachi para co-geração }\end{array}$ \\
\hline CFCL (Austrália) & Planar & Suportada no eletrólito & $\begin{array}{l}\text { Materiais, célula, } \\
\text { Emp, sistema }\end{array}$ & Desde 2001 IC cerâmico \\
\hline
\end{tabular}

*IC $=$ interconector, $* *$ Emp $=$ empilhamento

\section{CONFIGURAÇÕES}

Uma inspeção dos conceitos de engenharia usados pelas companhias revela que duas configurações de CCOS são as mais usadas: planar e tubular. Estas opções definem os materiais componentes e, principalmente, os métodos usados para processamento e conformação. Além disso, o tipo de configuração adotada também pode ser importante, dependendo da aplicação planejada para o dispositivo.

\section{Planar}

A configuração planar consiste em células unitárias de forma plana conectadas em série, e pode ser divida em duas configurações principais: as células suportadas no eletrólito e as suportadas no anodo (também chamadas de auto-suportadas), como mostrado na Figura 4. Podem ser citadas ainda as células auto-suportadas no catodo ou no interconector, e as suportadas externamente em um substrato (metálico ou cerâmico) poroso ${ }^{3,4}$.
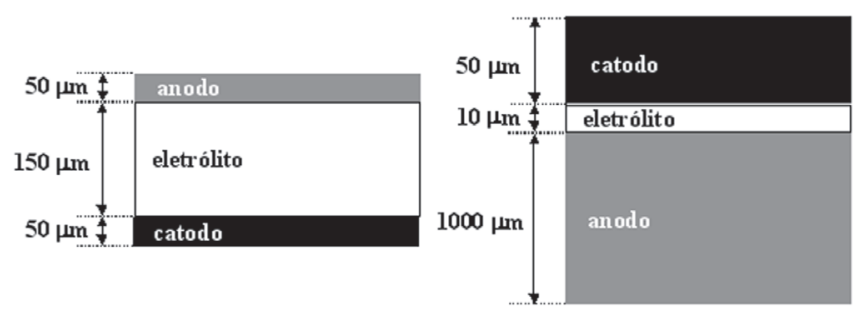

Figura 4. Diagrama da configuração planar de célula a combustível de óxidos sólidos unitária auto-suportada no eletrólito (esquerda) e no anodo (direita)

Um importante aspecto para o desenvolvimento da CCOS planar deve-se às maiores densidades de potência (até $~ 1,8 \mathrm{~W} / \mathrm{cm}^{2}$ ) deste design. Em contrapartida, os problemas relacionados ao processamento de camadas finas adjacentes dos componentes, de selagem e de compatibilidade térmica dos materiais, que acarretam problemas de durabilidade destes dispositivos, podem ser apontados como os grandes desafios do desenvolvimento desta configuração. Entretanto, progressos significativos têm sido alcançados na demons- tração da viabilidade de fabricação, no desempenho e na operação do design planar. De fato, este design é adotado pela maior parte das empresas envolvidas com esta tecnologia (Tabela 1).

Dentre as principais configurações de células planares, as células suportadas no eletrólito geralmente utilizam uma camada fina de ZEI de forma quadrada ou circular com área entre $\sim 25$ e $100 \mathrm{~cm}^{2}$ e espessura entre 100 e $200 \mu \mathrm{m}$. Devido à espessura relativamente grande do eletrólito e conseqüentemente maior resistência elétrica, essa configuração opera em temperaturas entre 850 e $1000{ }^{\circ} \mathrm{C}$. Nesse caso se faz necessário o uso de interconectores à base de $\mathrm{LaCrO}_{3}$, os quais são obtidos, geralmente, por processos cerâmicos tradicionais, como compactação ou colagem por fita ("tape casting”), seguido de tratamento térmico de sinterização. A principal vantagem dessa configuração é a longevidade do sistema, já que os interconectores cerâmicos são relativamente estáveis em atmosferas redutoras e oxidantes, não apresentando corrosão ou degradação significativas durante longos períodos de tempo ${ }^{1,4}$. No entanto, existe uma clara tendência por parte das empresas envolvidas com a tecnologia de CCOS na utilização de interconectores metálicos (ligas à base de $\mathrm{Cr}$ ou Fe) ${ }^{11}$, já que os interconectores cerâmicos têm um custo elevado e apresentam diferentes coeficientes de expansão térmica em atmosferas redutoras e oxidantes. Além disso, eles têm baixos valores de condutividades térmica e elétrica e são difíceis de conformar se comparados aos interconectores metálicos. A utilização de interconectores metálicos, por outro lado, implica na redução da temperatura de operação da célula, cujo principal empecilho é a redução da cinética nas reações eletroquímicas, aumentando dessa forma as polarizações por ativação e por queda ôhmica, além da redução da energia térmica extraída que pode ser utilizada para a alimentação de turbinas ou trocadores de calor. Apesar da boa condutividade térmica dos metais, que reduz os gradientes de temperatura do empilhamento e da entrada e saída de gases na célula, os altos coeficientes de expansão térmica das ligas metálicas, se comparados com o da ZEI, consistem em outro fator complicador para sua utilização.

Essa dificuldade foi parcialmente superada pela empresa Sulzer Hexis (Suíça), que utiliza em seus interconectores uma liga de cromo com $5 \%$ de ferro e $1 \%$ de ítria (óxido de ítrio) desenvolvida pela empresa austríaca Plansee; essa mesma liga também era utilizada nas células da Siemens. No entanto, o Cr dessas ligas metálicas pode difundir para os demais componentes da célula, aumentando sua degradação durante a operação $0^{4,12}$. 
Como a resistência elétrica do eletrólito é o maior obstáculo para a redução da temperatura de operação das CCOS, um dos principais focos das empresas e também um dos maiores desafios na tecnologia cerâmica é a produção de eletrólitos finos densos e mecanicamente resistentes. Nesse caso, o suporte da célula passa para um dos eletrodos e o anodo à base de níquel é o mais favorecido. Devido a sua boa condutividade elétrica, um anodo espesso (de $\sim 0,5$ até 1,5 $\mathrm{mm}$ ) de ZEI/Ni não adiciona resistência elétrica considerável à célula; além disso, esses compostos cerâmica-metal apresentam boa estabilidade mecânica, permitindo a fabricação de componentes com maiores dimensões. Essa configuração auto-suportada no anodo é adotada por várias empresas: General Electric (EUA) em sistemas portáteis de $20 \mathrm{~W}$ e até em sistemas híbridos (CCOS/turbina a gás) de multi-MW 3; Global Thermoelectric/Versa Power (Canadá) em um empilhamento de 84 células consistindo de 4 módulos com 21 células cada, gerando $2,3 \mathrm{~kW}$ (utilizando gás natural como combustível) a $750{ }^{\circ} \mathrm{C}$ por $25000 \mathrm{~h}$ de operação; esse mesmo sistema também foi submetido, com sucesso, a testes de durabilidade a 50 ciclos térmicos entre a temperatura de operação e a temperatura ambiente $^{13}$; Delphi/Pacific Nortwest National Laboratory (EUA), em unidades auxiliares de potência de dois empilhamentos de 30 células, gerando $1,6 \mathrm{~kW}$ a $750{ }^{\circ} \mathrm{C}^{14}$ e, Haldor Topsoe/Risoe National Laboratory (Dinamarca), utilizando catodos de LSCF, com temperatura de operação de $750{ }^{\circ} \mathrm{C}$, gerando $0,8 \mathrm{~W} / \mathrm{cm}^{2}$ a $0,7 \mathrm{~V}^{4,15}$.

Do ponto de vista da tecnologia cerâmica, a fabricação dos componentes das CCOS na configuração planar pode ser dividida em dois grupos: os processos particulados e os de deposição. Em qualquer caso o ponto chave do processo é a produção de eletrólitos densos. Todos esses processos têm demonstrado serem capazes de produzir eletrólitos com diversas espessuras, incluindo camadas finas de eletrólito para suporte em eletrodos. No caso dos métodos de deposição pode-se citar: deposição metálica em plasma de argônio ("sputtering"), recobrimento por imersão (“dip coating"), recobrimento sob rotação ("spin coating"), pirólise por jateamento ("spray pirolysis"), eletroforese, colagem por barbotina a vácuo ("vacuum slip casting"), deposição eletroquímica a vapor ("electrochemical vapor deposition" - EVD) e jateamento por plasma ("plasma spray") No caso dos métodos particulados tem-se, principalmente: a colagem por fita ("tape casting") e calandragem por fita ("tape calendering"). Esse último processo, utilizado pela General Electric (GE), consiste na formação contínua de uma camada de material termoplástico com espessura controlada pela distância entre dois rolos. Pós cerâmicos e aditivos orgânicos são misturados em um agitador para formar uma massa plástica e essa massa passa através de rolos que lhes dão a forma de uma folha de espessura controlada, a qual é tratada termicamente em altas temperaturas. Multicamadas são produzidas através de uma segunda passagem das folhas previamente laminadas pelos rolos. Utilizando técnicas de baixo custo para o processamento, a expectativa da GE é de que, após o projeto completo, o custo do $\mathrm{kW}$ das CCOS seja inferior a 400 dólares, seguindo as exigências estabelecidas pela sua parceria com o Departamento de Energia dos EUA (DOE) ${ }^{6,10}$

Outra variação importante da configuração planar, investigada pela $\mathrm{GE}^{1,3}$, é relacionada ao fluxo e à distribuição de gases, que podem ser arranjadas de várias maneiras: fluxo-cruzado ("cross-flow”), contra-fluxo ("counter-flow") ou co-fluxo ("co-flow"). A seleção do tipo de configuração de fluxo influencia de maneira importante a distribuição de temperatura e de corrente no empilhamento. Vários padrões de fluxo podem ser implementados, como serpentina, "Z", radial e espiral. Esses canais de fluxo podem ser estampados em corpos a verde ou usinados em peças sinterizadas. Nesse ponto, é interessante notar que a utilização de interconectores (ou suportes) metálicos facilita a conformação destes canais utilizando-se técnicas como estampagem ou usinagem. Além disso, devem ser incluídos na configuração planar distribuidores para o direcionamento dos gases do ponto de fornecimento para cada célula e remoção dos gases não reagidos e produtos da reação. Os distribuidores podem ser classificados como internos ou externos. Os distribuidores externos são construídos separadamente da célula ou do interconector. Os distribuidores internos são concebidos como parte da célula ou do interconector. $\mathrm{O}$ distribuidor deve ser um isolante elétrico para prevenir contato entre as células (curto-circuito) e deve ser concebido para ter baixa queda de pressão (em relação à queda de pressão em cada célula do empilhamento) provendo, assim, uma distribuição uniforme de fluxo. No design planar, os distribuidores de gases requerem selantes para impedir o vazamento ou a mistura dos gases. Entretanto, os projetos visam a minimização da área selada, pois os materiais selantes apresentam requisitos extremamente restritivos.

Dois métodos de selagem têm sido estudados: cargas compressivas (com ou sem guarnições - "gaskets") e selantes de alta temperatura. A selagem por compressão envolve o uso de uma carga mecânica para comprimir os componentes da célula. Esta selagem tem como vantagem a ausência de um material selante. Entretanto, a selagem através da compressão de superfícies irregulares e a minimização de tensões mecânicas são pontos críticos e, nesse sentido, as guarnições podem ser utilizadas para melhorar a estanqueidade e minimizar os efeitos da irregularidade das superfícies. Os selantes de alta temperatura incluem cimentos, vidros e vitrocerâmicas (borosilicatos e aluminossilicatos). O selante selecionado deve ter estabilidade em ambientes redutores e oxidantes, compatibilidade química com os demais componentes e propriedades de selagem e isolamento elétrico adequados ${ }^{1}$.

A Hexis destaca-se por desenvolver e testar em campo o conceito planar circular para geração estacionária de pequeno porte. No seu modelo o combustível é fornecido a partir do centro de uma célula, suportada no eletrólito, circular (12 cm de diâmetro) com um orifício central. Dessa forma, o combustível flui para a parte externa da célula, onde seu excedente é queimado. $\mathrm{O}$ ar é fornecido a partir da parte externa da célula e aquecido enquanto flui para o centro. $\mathrm{O}$ empilhamento deste sistema é de 70 células, operando a $950{ }^{\circ} \mathrm{C}$ e gerando 1,1 $\mathrm{kW}^{12}$. A Hexis possui 100 unidades de uma série pré-comercial em testes de campo. A análise dos dados preliminares destes testes já mostrou que esse modelo apresenta degradação sob compressão. A saída encontrada pelos pesquisadores da Hexis foi a substituição do eletrólito de ZEI por zircônia estabilizada com escandia (óxido de escândio) nas três primeiras unidades das extremidades de cada empilhamento reduzindo, dessa forma, a taxa de degradação em $62 \%$; porém, essa melhora no desempenho não se refletiu no custo do $\mathrm{kW} /$ h, já que os eletrólitos de zircônia estabilizada com escandia apresentam custos maiores que os tradicionais eletrólitos de $\mathrm{ZEI}^{16}$.

Outra configuração planar de destaque é desenvolvida em conjunto pelas empresas Mitsubishi Heavy Industries e Chubu Electric Power Company (ambas do Japão). Chamada de monobloco, com área de $20 \mathrm{~cm}^{2}$, é baseada em um eletrólito corrugado sobre o qual são depositadas as camadas dos eletrodos. Nessa concepção a própria célula possui canais para o fluxo de gases, simplificando o formato dos interconectores cerâmicos utilizados (Figura 5). O maior empilhamento dessa configuração consiste de 40 células unitárias gerando $2,5 \mathrm{~kW}$ a $1000{ }^{\circ} \mathrm{C}{ }^{17}$.

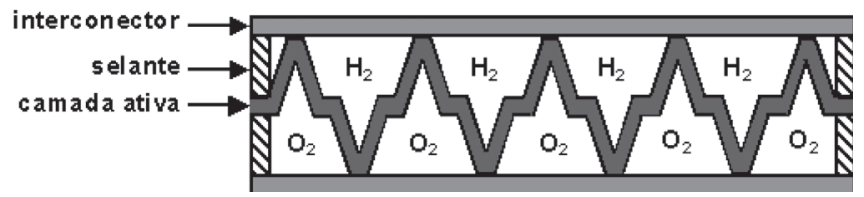

Figura 5. Configuração monobloco de célula planar, adotada pela Mitsubishi Heavy Industries/Chubu Electric Power Company. Adaptado da ref. 17 
Como exemplo de configuração suportada externamente, podese citar os desenvolvimentos da Rolls Royce (Inglaterra) ${ }^{18}$ e da Kyocera (Japão) ${ }^{19}$, nos quais pequenas tiras de eletrodos e eletrólitos são depositados sobre um substrato cerâmico poroso provendo suporte mecânico à célula. As células unitárias são conectadas em série também por tiras de interconectores cerâmicos. Essas células estão sendo operadas a $950{ }^{\circ} \mathrm{C}$ com objetivos de geração de potência da ordem de $\mathrm{kW}$.

Além das empresas já citadas, várias outras utilizam a configuração planar, como BMW (Alemanha), utilizando catodos de LSCF e com densidade de potência de $1,6 \mathrm{~W} / \mathrm{cm}^{2}$ a $0,7 \mathrm{~V}$ e $750{ }^{\circ} \mathrm{C}{ }^{20}$; Nihon Gaishi (NGK - Japão) ${ }^{4}$ e Pirelli (Itália), que utilizam eletrólitos de céria dopada com gadolínea, catodos de LSCF e anodos contendo $\mathrm{Ni}, \mathrm{Cu}$ e céria dopada com gadolínea.

\section{Tubular}

A configuração tubular pode ser considerada a mais desenvolvida do ponto de vista de estabilidade em operação por longos períodos de tempo. Seu empreendedor mais atuante e avançado nas últimas décadas foi a Westinghouse, atualmente Siemens Power Generation. Esta companhia já acumula mais de $40 \mathrm{mil} \mathrm{h}$ de operação de CCOS tubular com potência de $100 \mathrm{~kW}$, com índice de degradação de desempenho de $\sim 0,1 \% / 1000 \mathrm{~h}$.
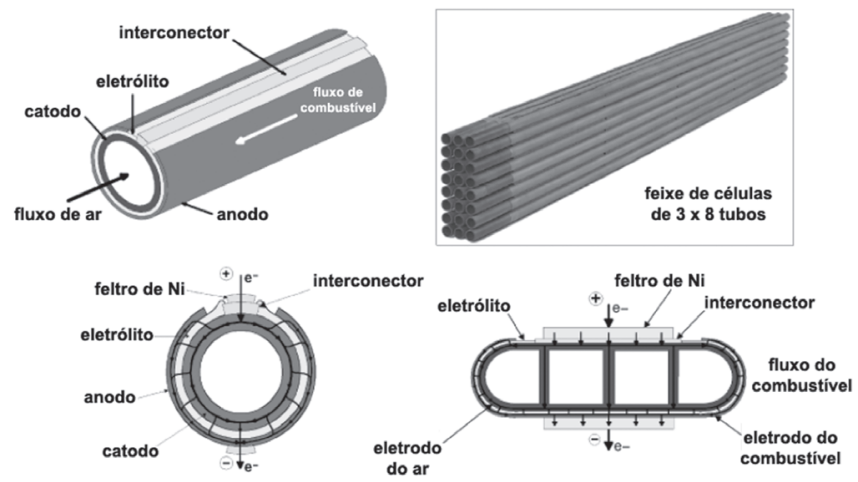

Figura 6. Design do tubo, feixe de células e tubo achatado da Siemens Power Corporation. Adaptado da ref. 4

Os tubos deste design são fechados em uma extremidade. Para operação da célula, o oxidante é introduzido através de um injetor de alumina (óxido de alumínio) posicionado dentro do tubo. O oxidante é injetado próximo à extremidade fechada do tubo. O combustível flui através da superfície externa da célula tubular na direção da parte fechada do tubo para a parte aberta. Na extremidade aberta, o ar deficiente em $\mathrm{O}_{2}$ e o excesso de combustível são queimados. Tipicamente $50-90 \%$ do combustível são consumidos na reação eletroquímica da célula. Parte do combustível em excesso é re-circulado e o restante é queimado para pré-aquecer os gases de entrada. A temperatura dos gases de exaustão da célula é entre 600 e $900{ }^{\circ} \mathrm{C}$, dependendo das condições de operação.

Esta configuração de CCOS tubular é baseada na conformação de camadas finas dos componentes cerâmicos na forma de tubos. Em suas configurações inicias, o tubo cilíndrico era feito de zircônia estabilizada com cálcia (óxido de cálcio). Este tubo poroso funcionava como suporte estrutural, sobre o qual os componentes eram depositados, e permitiam a passagem de oxigênio para o catodo durante a operação. Este tubo poroso era fabricado por extrusão seguida de sinterização em altas temperaturas. Embora suficientemente poroso, o tubo apresentava uma impedância natural ao fluxo de gás em direção ao catodo. Com objetivo de minimizar esta impedância ao fluxo de ar, a espessura das paredes foi diminuída de 2 para 1,2 $\mathrm{mm}$. Mais tarde, este tubo foi eliminado e substituído por um tubo à base de $\mathrm{LaMnO}_{3}$. Este tubo de manganita de lantânio é o catodo e serve como suporte estrutural sobre o qual os demais componentes são depositados. Além da eliminação do tubo de suporte externo, o comprimento ativo dos tubos foi aumentado para aumentar a potência gerada por célula unitária. Uma maior potência por célula diminui a quantidade necessária de células em um empilhamento para uma determinada potência final. O comprimento ativo (o comprimento usado para interconexão) aumentou de 30 cm (até 1986) com o suporte tubular poroso de zircônia estabilizada com cálcia para $150 \mathrm{~cm}$ no protótipo atual suportado no catodo. O diâmetro do tubo aumentou de 1,6 para 2,2 cm. O tubo atual, catodo de LSM, com 2,2 cm de diâmetro, 2,2 $\mathrm{mm}$ de espessura da parede e comprimento total de $180 \mathrm{~cm}$, é fabricado por extrusão e sinterizado até uma porosidade final de 30-35\%.

O eletrólito ZEI é depositado na forma de uma camada de $40 \mu \mathrm{m}$ de espessura por deposição eletroquímica a vapor. Neste processo, cloretos de zircônio e de ítrio são volatilizados em uma proporção determinada e injetados, junto com uma mistura de hidrogênio e argônio, sobre a superfície externa do tubo poroso do catodo. Um fluxo de oxigênio e vapor de água é injetado internamente ao tubo. No primeiro estágio da reação ocorre a difusão molecular do $\mathrm{O}_{2}$, vapor, cloretos metálicos e $\mathrm{H}_{2}$, através do catodo poroso, que reagem preenchendo os poros do catodo. As condições experimentais, como temperatura, pressão e taxas de fluxos de gases são definidas de forma a favorecer a termodinâmica do processo. No segundo estágio da reação, após o preenchimento dos poros, ocorre o transporte eletroquímico dos íons oxigênio através da camada já depositada de ZEI nos poros para manter a eletro-neutralidade. Os íons $\mathrm{O}^{2-}$ ao atingirem o lado de baixa pressão parcial de $\mathrm{O}_{2}$ (superfície externa) reagem com os cloretos formando o filme do eletrólito. A técnica EVD resulta em camadas finas uniformes e estanques do eletrólito sobre o catodo poroso. Entretanto, esta técnica é complexa, de alto custo e é difícil a produção de grandes quantidades. A fabricação de filmes de eletrólitos de ZEI por meio de técnicas mais viáveis, como plasma spray, seguida de sinterização, está sendo investigada.

$\mathrm{O}$ anodo ZEI/Ni, com espessura de 100-150 $\mu \mathrm{m}$ é depositado sobre o eletrólito por meio de um processo em duas etapas: na primeira, uma pasta de pó de Ni é aplicada sobre o eletrólito; na segunda, partículas de ZEI são depositadas ao redor das partículas de Ni por EVD. A deposição de uma pasta de ZEI/Ni diretamente sobre o eletrólito, seguida de sinterização também fornece anodos com boas propriedades.

$\mathrm{O}$ interconector à base de $\mathrm{LaCrO}_{3}$ é depositado na forma de uma tira ao longo do comprimento do tubo do catodo com $85 \mu \mathrm{m}$ de espessura e $9 \mathrm{~mm}$ de largura por jateamento por plasma seguido de sinterização.

Outra importante propriedade deste design é que as CCOS tubulares suportam mais de 100 ciclos térmicos entre a temperatura de operação e a temperatura ambiente, sem nenhum dano mecânico ou degradação de desempenho. Por outro lado, a alta resistência ôhmica deste design obriga a operação das células acima de $900{ }^{\circ} \mathrm{C}$ para alcançar densidades de potência de $200 \mathrm{~mW} / \mathrm{cm}^{2}$.

As CCOS tubulares também foram testadas em condições pressurizadas de até 15 atm usando $\mathrm{H}_{2}$ e gás natural. Sob pressão, a célula gera maiores densidades de potência, devido ao aumento do potencial de Nernst e à redução da polarização catódica, permitindo uma maior eficiência do empilhamento. Para se construir um gerador elétrico, as células unitárias individuais são conectadas em série e em paralelo formando um feixe semi-rígido, que é a unidade de um empilhamento. Estes feixes são agrupados e conectados em série para a montagem da CCOS. 
As principais vantagens desta configuração são a estabilidade térmica e a eliminação do uso de selantes. Por outro lado, estas células têm baixa densidade de potência quando comparadas ao design planar e envolvem processos de custo elevado para sua fabricação ${ }^{1}$.

Os avanços atuais da Siemens visam a fabricação de tubos achatados e tubos com seção triangular, que aumentam em cerca de $40 \%$ a densidade de potência da CCOS tubular convencional. Um procedimento similar, mas com tubos de anodo como suporte, é adotado pela companhia japonesa Kyocera ${ }^{4}$. Outras companhias japonesas têm investido nesta configuração como, por exemplo, a Toto $^{21}$, que tem buscado processos de fabricação de menor custo e optou por diminuir o comprimento dos tubos para $0,5 \mathrm{~m}$. A Acumentrics (EUA) está desenvolvendo tubos suportados no anodo com $45 \mathrm{~cm}$ de comprimento e diâmetro externo de $15 \mathrm{~mm}$. Esta companhia americana testa sistemas tubulares alimentados por gás natural com potência entre 2 e $10 \mathrm{~kW}{ }^{4}$.

Uma outra possibilidade da configuração tubular é o chamado design micro-tubular. Neste caso, são usados tubos com diâmetro menor que $5 \mathrm{~mm}$. Este tipo de configuração tem sido planejado para as aplicações em unidades auxiliares de potência.

\section{APLICAÇÃo E COMERCIALIZAÇÃo}

As CCOS têm como principal aplicação a geração estacionária de energia elétrica. Esse segmento pode ser dividido em duas principais categorias: grande porte, com potência $>10 \mathrm{~kW}$ e pequeno porte, com potência $<10 \mathrm{~kW}$. Recentemente, a aplicação de baixa potência em unidades auxiliares de potência para uso, por exemplo em veículos, tem alcançado relevância no campo das CCOS.

No contexto da geração estacionária de grande porte, as células a combustível de carbonato fundido lideram as unidades comercializadas. Entretanto, a CCOS começa a se destacar neste cenário e possui o maior número de companhias envolvidas no desenvolvimento da tecnologia, com participação destacada de empresas japonesas. Embora o número de unidades instaladas tenha crescido e nenhuma companhia envolvida neste desenvolvimento tenha encerrado suas atividades em 2005, a comercialização de sistemas células a combustível para este segmento avança lentamente e ainda necessita de grandes investimentos. A CCOS tem menor número de unidades de alta potência em teste de campo, quando comparada a outros tipos células a combustível. Isto é devido ao fato de que não há uma única companhia que tenha resolvido sozinha todos os desafios para colocar no mercado um número apreciável de sistemas ${ }^{22}$. No contexto da geração de altas potências, é interessante notar o desenvolvimento de sistemas modulares acoplados a turbinas a gás. A GE (EUA), Rolls Royce (Inglaterra) e Siemens (EUA) são três exemplos de grandes companhias que adotam esta estratégia. Os benefícios dos sistemas híbridos (CCOS e turbinas a gás) incluem maior eficiência ( $\geq 80 \%$ ), menor custo de vida útil e maior recuperação do calor gerado. A GE Energy testa atualmente sistemas sub-MW e ganhou, recentemente, junto com outras cinco empresas, um contrato competitivo do Departamento de Energia dos EUA (DOE) de 83 milhões de dólares para desenvolver em 10 anos um sistema CCOS-turbina a gás de multi-MW abastecida com carvão gaseificado. A Rolls Royce pretende demonstrar em 2008 seu sistema híbrido de $1 \mathrm{MW}$, que consiste de quatro CCOS de $250 \mathrm{~kW}$, e atualmente testa seu sistema de $80 \mathrm{~kW}$. Além das empresas citadas, entre os principais empreendedores desta categoria de CCOS, podem ser incluídas as companhias japonesas, como por exemplo J-Power, Mitsubishi Materials (MM), Mitsubishi Heavy Industries (MHI) e Chubu Electric Power. Todas usam os designs planar ou tubular em seus projetos. A MM visa o desenvolvimen- to de células com o eletrólito à base de galato de lantânio e anunciou em janeiro de 2005 a operação contínua a $800{ }^{\circ} \mathrm{C}$ por $1000 \mathrm{~h}$ de seu protótipo de $1 \mathrm{~kW}$ com eficiência de $\sim 57 \%$. A MHI e a JPower iniciaram a operação de um sistema de $25 \mathrm{~kW}$ construído em cooperação e pretendem chegar a sistemas de $50 \mathrm{~kW}$ para comercialização nos próximos anos. A companhia Z-Tek (EUA) desenvolve células planares e demonstrou a operação por $15000 \mathrm{~h}$ de um empilhamento de $1 \mathrm{~kW}$ e, atualmente, opera um sistema de $25 \mathrm{~kW}$ a gás natural.

O mercado de geração estacionária de pequeno porte $(<10$ $\mathrm{kW}$ ) permaneceu estável nos últimos 3 anos, sendo que apenas $25 \%$ deste corresponde às CCOS, o restante é dominado pelas células a combustível poliméricas. No entanto, no último ano várias empresas têm se envolvido com $\mathrm{P} \& \mathrm{D}$ de CCOS de baixa potência e espera-se nos próximos anos maior participação desta tecnologia na produção de energia estacionária até $10 \mathrm{~kW}$. De fato, pode-se notar que a maioria das empresas (Tabela 1) que utilizam esta tecnologia apresenta seus produtos nessa faixa de potência ${ }^{1,4,6,10}$.

\section{CONCLUSÃO}

Apesar dos materiais comumente utilizados em CCOS serem essencialmente os mesmos há várias décadas, nota-se uma tendência na adoção de catodos da família LSCF e interconectores metálicos. Eletrólitos alternativos são menos comuns e sua aplicação é preterida frente à estabilidade e o conhecimento acumulado sobre as cerâmicas à base de zircônia.

O design planar é escolhido pela maior parte dos desenvolvedores. Por outro lado, suas principais limitações são relativas à baixa estabilidade à ciclagem e à degradação de desempenho em longos períodos de tempo. No caso tubular, as relativas baixas densidades de potência são compensadas pela boa estabilidade e baixa degradação. Neste caso, o alto custo envolvido em sua fabricação é um importante limitador. No entanto, estudos relativos à deposição de camadas de eletrólito sob tubos porosos de anodo e catodo devem ser incentivados. $\mathrm{O}$ design planar apresenta maior densidade de potência e facilidade em sua produção. Este tipo de design deve ser escolhido em pesquisas inicias sobre CCOS, devido a sua relativa simplicidade. Nesse sentido, o incentivo à pesquisa de novos materiais selantes e interconectores torna-se importante. Neste contexto, é possível que o desenvolvimento do design tubular seja preterido em relação às CCOS com design planar.

O desenvolvimento tecnológico e comercial das células a combustível de óxidos sólidos tem avançado gradualmente. Até o momento estes dispositivos não são comercializados e um maior desenvolvimento da tecnologia é necessário para que dispositivos confiáveis e competitivos surjam no mercado. Por outro lado, não foi encontrado nenhum impedimento técnico que inviabilizaria esta tecnologia. Um prognóstico exato sobre quais materiais e configuração atingirão o estágio de desenvolvimento comercial ainda é difícil, assim como a certeza da relevância do papel desta tecnologia na geração de energia elétrica a curto prazo. Entretanto, os elevados investimentos por parte de desenvolvedores europeus, americanos e japonenes, e os atraentes aspectos ambientais da tecnologia, somados ao número e ao porte das empresas empreendedoras, sugerem que as células a combustível de óxidos sólidos deverão atingir um alto grau de desenvolvimento, o que deverá permitir sua inserção no mercado de geração de energia elétrica.

\section{AGRADECIMENTOS}

À FAPESP (03/08793-8, 99/10798-0 e 98/14324) e ao CNPq (306496/88-7, 300934/94-7, 401051/03-0 e 301661/04-9). 


\section{REFERÊNCIAS}

1. Singhal, S. C.; Kendall, K.; High-temperature Solid Oxide Fuel Cells: Fundamentals, Design and Applications, $1^{\text {st }}$ ed., Elsevier: New York, 2004; Singh, P.; Minh, N. Q.; Int. J. Appl. Ceram. Technol. 2004, 1, 5.

2. Wendt, H.; Gotz, M.; Linardi, M.; Quim. Nova 2000, 23, 538.

3. Minh, N. Q.; Solid State Ionics 2004, 174, 271

4. Blum, L.; Meulenberg, W. A. ; Nabielek, H.; Steinberger-Wilckens, R.; Int. J. Appl. Ceram. Technol. 2005, 2, 482.

5. de Florio, D. Z.; Fonseca, F. C.; Muccillo, E. N. S.; Muccillo, R.; Cerâmica 2004, 50, 275; Steele, B. C. H.; Heinzel, A.; Nature 2001, 414, 345; Minh, N. Q.; J. Am. Ceram. Soc. 1993, 76, 563.

6. Minh, N. Q.; Pan-American Advanced Studies Institute, Materials for Energy Conversion and Environmental Protection, Rio de Janeiro, Brasil, 2003.

7. Attryde, P.; Baker, A.; Baron, S.; Brandon, N. P.; Corcoran, D.; Cumming, D.; Duckett, A.; El-Koury, K.; Haigh, D.; Harrington, M.; Kidd, C.; Leah, R.; Lewis, G.; Matthews, C.; Maynard, N.; McColm, T.; Selcuk, A.; Schmidt, M.; Trezona, R.; Verdugo, L.; Proceedings of Solid Oxide Fuel Cells IX, Quebec, Canadá, 2005.

8. Akikusa, J.; Yamada, T.; Kotani, T.; Murakami, N.; Akbay, T.; Hasegawa, A.; Yamada, M.; Komada, N.; Nakamura, S.; Chitose, N.; Hirata, K.; Sato, S.; Miyazawa, T.; Shibata, M.; Hosoi, K.; Nishiwaki, F.; Inagaki, T.; Kanou, J.; Ujie, S.; Matsunami, T.; Nakajima, H.; Nishi, J.; Sasaki, T.; Yoshida, H.; Hashino, K.; Kawano, M.; Yamasaki, S.; Takita, Y.; Ishihara, T.; Proceedings of Solid Oxide Fuel Cells IX, Quebec, Canadá, 2005.

9. de Florio, D. Z.; Esposito, V.; Savo, G.; Di Bartolomeo, E.; Traversa E.; Proceedings of Solid Oxide Fuel Cells VIII, Paris, França, 2003.
10. Williams, M. C.; Strakey, J. P.; Surdoval, W. A.; Proceedings of Solid Oxide Fuel Cells IX, Quebec, Canadá, 2005.

11. Zhu, W. Z.; Deevi, S. C.; Mater. Sci. Eng., A 2003, 348, 227.

12. Schmidt, M.; Fuel Cells Bull. 1998, 1, 9.

13. Tang, E.; Prediger, D.; Pastula, M.; Borglum, B.; Proceedings of Solid Oxide Fuel Cells IX, Quebec, Canadá, 2005.

14. Mukerjee, S.; Haltiner, K.; Shaffer, S.; Meinhardt, K.; Chick, L.; Sprenkle, V.; Weil, S.; Kim, J. Y.; Proceedings of Solid Oxide Fuel Cells IX, Quebec, Canadá, 2005.

15. Fontell, E.; Hussila, M.; Hansen, J. B.; Pålsson, J.; Kivisari, T.; Nielsen, J. U.; Proceedings of Solid Oxide Fuel Cells IX, Quebec, Canadá, 2005; Christiansen, N.; Kristensen, S.; Holm-Larsen, H.; Larsen, P. H.; Mogensen, M.; Hendriksen, P. V.; Linderoth, S.; Proceedings of Solid Oxide Fuel Cells IX, Quebec, Canadá, 2005.

16. Hoffmann, J.; Woski, M.; Denzler, R.; Doggwiler, B.; Doerk, T.; Proceedings of Solid Oxide Fuel Cells IX, Quebec, Canada, 2005.

17. Nakanishi, A.; Hattori, M.; Sakaki, Y.; Miyamoto, H.; Aiki, H.; Takenobu, K.; Nishiura, M.; Proceedings of the Fifth European SOFC Forum, Lucerne, Switzerland, 2002.

18. Gardner, F. J.; Day, M. J.; Brandon, N. P.; Pashley, M. N.; Cassidy, M.; J. Power Sources 2000, 86, 122.

19. http://global.kyocera.com/news/2003/1205.html, acessada em Abril 2006.

20. Schiller, G.; Franco, T.; Lang, M.; Metzger, P.; Störmer, A. O.; Proceedings of Solid Oxide Fuel Cells IX, Quebec, Canadá, 2005.

21. Saito, T.; Abe, T.; Fujinaga, K.; Miyao, M.; Kuroishi, M.; Hiwatashi, K.; Ueno, A.; Proceedings of Solid Oxide Fuel Cells IX, Quebec, Canada, 2005

22. Baker, A.; Adamson, K. - A.; Am. Ceram. Soc. Bull. 2006, 85, 22. 